\title{
Indigenous Counseling System of Oromo Community in Ethiopia
}

\author{
Getachew Abeshu, PhD \\ Continuing and Distance Education Coordinator, College of Education and Behavioral Sciences \\ Jimma University
}

\begin{abstract}
Oromo as a larger community in Ethiopia has its own wisdom and way of living which was not studied well. Accordingly, this study was intended to analyze the efficacy of indigenous counseling approaches ever practiced among Oromo community. Five districts employing indigenous counseling services in their intervention were covered utilizing purposive sampling. Qualitative study design involving explanatory models, semi-structured interview, observation and focus group discussions were used to gather information. The study result discloses that counseling is tradition among Oromo community even if higher institutions and the government didn't incorporate the cultural values of counseling in the education curriculum. Indigenous counseling system was mistreated area prone to alteration from the usual business. Moreover, cultural invasion by alien religious denominations, high intrusion of the dominant ruling classes through times and displacement of the local natives by the pseudo-urbanization has a moribund effect in stunting indigenous counseling systems. The methods employed, techniques and procedures used by indigenous counselors are well organized aided by the rules and regulations of Gada administration enacted on the general assembly. Integrating indigenous counseling to the education curriculum of the country and adaptation of the modern counseling methods to the level of harmonizing and pertaining to the local community custom was recommended.
\end{abstract}

Key terms: Gadaa, general assembly, indigenous counseling, modern counseling, Oromo community

DOI: $10.7176 /$ RHSS/9-5-06

Publication date:March $31^{\text {st }} 2019$

\section{Introduction}

Background: Rogers (1961) defined guidance and counseling as an optimal helping relationship created by a person who is psychologically mature to facilitate the growth of others who are vulnerable. Besides, Perez (1965) suggests that it is an interactive process co-joining the counselee who needs assistance and the counselor who is trained and educated to give this assistance the goal of which is to help the counselee to deal more effectively with himself and the reality of his environment. Nevertheless, the concept of psychology, its theories and methods as understood by westerners, are alien to the thinking of Africans. Africans in general have not received the need for systematic application of psychology and its principles. Yusuf (1977), for example, suggested that traditionally Africans had their own crude ways of collecting team members for hunting and cattle herding assignments. They had their own wise men with the ability to heal the physic problem of their sick. Even today, there are some African countries whose curriculum is void of the need of psychology. Ethiopia is a case in point.

Indigenous knowledge is defined as a body of knowledge built up by a group of people through generations of living in close contact with nature (Johnson, 1992). Sinha on the other hand remarked that indigenous counseling attempts to develop a behavior science that matches the socio-cultural realities of one's own society (Sinha, 1990). So, if a person is counseled in his/her cultural context; really counseling is likely to take place. A counselor with such a background is expected to come up with informed options to counseling sessions in the relationship. However, a study indicated that, to a certain extent indigenous counseling has a reaction to or rejection of the dominance of Western approaches in a culture (Sinha, 1990). Thus, resolving theoretical and conceptual issues about the identity of African indigenous knowledge systems, in relation to the Western approach, is in fact one of the many challenges confronting African philosophers, historians, anthropologists and educators.

It is appropriate at this juncture to say something about African psychologists and psychiatrists that are trained in foreign countries which reveal that African psychiatrists and psychologists receive their training in the environment where they intended to work. These trainees should be cautious in employing 'Euro-American' concepts and techniques when dealing with Africans. Abdul Basit in his study of counseling principles, revealed about the cultural perspectives of modern counseling and its application as opposed to Africans allied to the Westerners stating that 'modern psychotherapy, as it emerged in the west, was deeply influenced by western thinkers who represented the religious-cultural traditions, historical symbols, and narratives of Western society' (Abdul Basit, 2005). Hence, this study attempted to fill conceptual and technical gaps of application in real environment with the existing multicultural perspectives.

Ethiopia, as a country with diverse culture has vast un-researchable areas of life situation regarding psychology of life, counseling tradition, egalitarian way of administration, indigenous knowledge and arts, interesting systems of interaction and prosperous life styles didn't get attention from the elites to organize and document what is available in the community as an asset for Africans and the world. In Ethiopia, as stated by 
Wemlinger, the Oromo exercised power over their own identities, defined their own cultural and religious character, and have maintained their ethnic distinctiveness (Wemlinger, 2008).

Oromia is one of the largest regions in Ethiopia covering huge geographical locations. Most of the populations residing in the region are natives who use Afan Oromo as own father tongue except very few immigrants coming to the region because of urbanization and colonial domination of previous feudal regime northerners. There are diversified agricultural works in the region from complete nomadic life of herds to the settled land tilling activity that are almost based on family support standard (Asafa, 2012). The original religion of Oromo community is 'Wakefata - Waaqeffataa' which is derived from 'Waaqaa' (God, the creator of all things - the land and the universe). In the pre-colonial Oromo society, the core of Oromo social, economic, political, philosophical, and spiritual life was a holistic institution known as Gada. Under Gada, Oromo's believed in Waaqa (God). Waaqa is one as a supreme being, but is also many as ayyaana. Ayyana exist in everybody and everything in the universe. In Oromo religion, Waaqa creates and regulates the existence of all animate and inanimate, material and nonmaterial nature and places them in a well-balanced cosmic order (Oromo religion, website [Retrieved March, 2000]). In the culture, there are different systems operating to keep ones mode of life acceptable, better and active in the community settings. Among these, counseling is the one that has got due emphasis from the community leaders, elders and fathers to keep ones existence on the appropriate truck of life.

The present study therefore, attempted to explore current status and development of African psychology, specifically Ethiopian context intending to counseling of people with different problems (mental, emotional, and social problems), youth 'kuchu' counseling (developmental), marital and family counseling. Lack of proper documentation on the prevalence, level of severity, geographical disparity, lack of standardized assessment tools and methods made the approach more demanding. Withstanding these all difficulties, this work will hopefully awakening the consciousness of African scholars in identifying and organizing indigenous counseling principles and therapeutic techniques available in the community for the benefit of Africans considering individuals and groups who are in need of the service.

Statement of the problem: Psychology is not well known and developed in Africa. Nsamenang (2007) disclosed that Africa has been and remains a major recipient of external influences that have been imposed unsolicited and scientific psychology arrived in Africa with colonization in the context of anthropological research as well as in allied service sectors like health, education and evangelism. The evolution and development of scientific psychology in sub-Saharan Africa has not been uniform (Nsamenang \& Lamb, 1995). He further narrated that variation exists across and within countries, regions, and language blocks in the orienting models, resources, conditions for training, research and applications as well as in the number of psychologists and their integration into research, policy and service programs. Whereas countries like Cameroon, Chad, and Gabon, have been 'struggling' to establish the discipline, formal psychology institutions and services already exist in Ethiopia, Ghana, Kenya, Liberia, Namibia, Nigeria, Uganda, Zambia and Zimbabwe.

Yusuf (1977) remarked that the non-existence of both theoretical and applied psychology in most African educational system, especially Ethiopia made the problem significant. Lack of the practical techniques and principles appropriate to the nation is another area. Foreign professors for foreign students have written all the reported research on African psychology. These and others made psychology to hold inherent problems of development in Africa. Consequently, Nsamenang and Dawes (1998) expressed that the term psychology is not understood as its function in the relevant African countries since all the definition and objectives are overwhelmed by jargons of the Western community. No adequate research has been done in the field of psychology in Africa when compared to other disciplines. The few American and European psychologists carrying out research in Africa also utilized the western frame of reference to examine African problems (Yusuf, 1977). Although they have made numerous original researches, their work was necessarily handicapped by their philosophical perspectives, by methodological problems, by absence of systematic synthesis, and by their align backgrounds. In general terms, localizing their research outputs to the community was their problem.

Hence, it is hoped that this research undertaking will generate genuine discussion and debate among concerned scholars. Additionally, having acquaintance to culturally diverse community counseling system is so indispensable to fill the gap found in the field. In a multicultural country like Ethiopia, where different counseling traditions in the daily life of the society are requisite, organizing the locally available principles, techniques and modes of counseling is an essential component in the study. Accordingly, in Ethiopia where the concept of counseling is also unknown to most people, that is, the confusion made between indigenous counseling mode and modern/Westerner/ counseling system, there is a need to ponder some of the following research questions to settle the argument to some extent. The study questions therefore were:

- Who are said to be counselors in Ethiopian context in the indigenous counseling scheme?

- What are the major techniques and procedures employed by these counselors?

- How can they communicate with clients and conduct the sessions?

- What are the relations and differences between Oromo indigenous counseling and the Western counseling systems? 
Objectives of the study: The study was mainly designed to explore the indigenous counseling systems functioning in Ethiopia in relation to the Western counseling scheme with great emphasis to identify principles and techniques relevant to the region, specifically Oromo community of Ethiopia.

The specific objectives of the study are to:

- Identify professional expertise working in the indigenous counseling system in the country;

- Find out the techniques, principles and procedures followed by indigenous institutions;

- Examine the existing case approach in practice and search for clients;

- Assess the existing therapeutic relationships and differences between counseling schemes.

Significance of the study: In Africa, specifically Ethiopian, all cultures needs to contribute for the economic, social and political development of the country. To do so, they require more trained personnel armed with the theoretical and practical aspect of guidance and counseling. What is more is development of localized guiding principles; techniques and methodologies incorporating current issues of counseling that initiates the researcher to more focus on the target population. These few points were listed to indicate the significance of counseling in the socio - psychological and economic development of Ethiopia today. Since there is no precedence or history for this field in the country, it must be realized that all efforts are of a pioneering nature. It also paves way for African researchers and psychologists review their own indigenous counseling customs accessible in their respective community. This signifies that certain forms of customary relationships are mandatory in leading community life if organized, sequenced and systematically arranged. It additionally paves way for Institutions incorporate well organized localized counseling custom in their curriculum for the betterment of psychological theories and principles significant to the country. The organized principles and techniques better facilitate counseling communications or multicultural counseling approaches.

Scope of the study: The study was originally designed to assess indigenous counseling systems employing five regional states covering at least twelve districts of these five regions. Due to certain confounding factors and other momentous challenges, the study was geographically enclosed to one region where it only focuses on the indigenous counseling system that involved only five zones of Oromia Regional State.

\section{Methodology}

Methods: Qualitative methods are best for researching many of the why and how questions of human experience (Given, 2008). The aim is, as a psychologist seeking in-depth understanding of human behavior and the reasons that govern such behavior qualitative research activity was contrived. Corbin (1986) believes that qualitative research enables us to make sense of reality, to describe and explain the social world and to develop explanatory models and theories. He further outlines that, it is the primary means by which the theoretical foundations of social sciences may be constructed or re-examined. Hence, qualitative research design employing exploratory method of study had been carried out on the target population to gather information on the techniques applied or else experienced in the community for counseling purpose.

Population and sampling: The sources of information for this study were elders (elder counselors), community leaders (Aba Gadaa's), religious and ritual leaders, and other influential peoples in the community. Employing purposive sampling technique, five zones/locale of Oromia were selected as potential study areas presuming that they exploit indigenous counseling system when compared to other zonal administrations. It was also recommended by experts working on cultural studies in the region where indigenous Oromo culture is highly practiced in terms of counseling and 'Gadaa' Administration. Asefa (2012) affirms that Gadaa is a customary system of governance used by the Oromo people in Ethiopia developed from knowledge gained by community experience over generations. The system regulates political, economic, social and religious activities of the community. Based on this presumption, samples were drawn from Gadaa institutions with the strong involvement of experts from Sarbo (1), Kuyyu (2), Galan (Bushoftu - 8), Guji (6) and Borana (2) as study participants. The total sample sizes were nineteen counselors and community 'Gadaa' leaders.

Data Collection instruments: Data was collected from the subjects (primary source) employing interview, observation and Focus Group Discussion (FGD). Semi-structured interview guides were developed for respondents less than six and focus group discussion conducted with two groups (Tulama \& Guji) as the target samples. Non-participant observation was also conducted at and around counseling areas at the spots of services. Incidental and informal discussion also had been held with community elders, experts and prominent figures.

Data analysis: Based on the basic interview and focus group discussion results, the investigator described the interview outcomes accordingly and stated results of focus group discussion in terms of words. The recorded interview results were transcribed and translated from Afan Oromo language in to English which in turn has been discussed in terms of statements. The results obtained through interview and observation memos were transcribed and carefully divided/grouped/coded in to meaningful analytical units/segments and analyzed. Based on the study results obtained from respondents, conclusion and the study gaps identified for further research were drawn. 


\section{Results and Discussion}

Backgrounds of the respondents - Five elder counselors from three areas (Sarboo, Kuyyu and Yaa'a Bal'oo) and fourteen Gadaa leaders 'hayyuu', which is to mean 'elites', from (Bushoftu and Bule Horaa) involved in the study. Almost all of them were/are influential figures among the community equipped with all the indigenous knowledge systems.

Role and accountability of the elders: Respondent counselors assert that they are counselors, heads of the family and leaders of the local community. They engage in advising, teaching, guiding, reconciling, and counseling the community. A respondent from Jimma expressed: My responsibility is elder counselor in the community responsible giving service in the area (Sarbo). I am head of the family nominated by the community assembly to reconcile, counsel and lead the public on community council. This council is headed by family members coming together to organize rules and regulations serving as a covenant among the community. As indicated above, the elder counselor is responsible treating the problems arise by community and family before it aggravates. Likewise, the elder counselor was chosen by the general assembly as to serve and acts as reconciler, marriage advisor, imperative person among neighbors, and devoted person in respecting people and rules of fathers in the relationship Besides his acceptance among the community, ability to narrate community rules and regulations orally among the meeting gave him position to be elected as elder counselor to shoulder multiple responsibilities.

Elder counselors, according to the result of this study, discloses that all areas under study perform counseling employing indigenous modes of counseling scheme that keeps the community in to balance in having well established and peaceful life styles albeit high external intrusions. The name given to the elder counselor is 'Aba kuna' which is common to Kuyyu /Salale/ Oromo. The purpose of Aba Kuna and elder counselor is all the same with its hierarchy of services. The elder /Aba Kuna/ serves as a counselor, leader and trainer for individuals seeking assistance in the local contexts. The culture can serve as the abiding principle where people can lead serene life in all its interaction in the locality without any tension, disturbances, chaos, presuming that the legal values and entities are enforced by elder counselors. Accordingly, Aba Kuna's work hard in providing group counseling to the community using clusters based on geographical locations as well.

The concept of counseling everywhere in the community is the same which is to mean directing, guiding, leading, advising, providing options of action to choose and carry out discussion with the problem person for the benefit of the individual, family and community. The community law is the abiding rules of procedure that assist the counselors perform all duties in line with the interests of the society helping the client considering "what is good or bad in life'. Moreover, the study result revealed that counseling at family position begins after the child acquires 'afaan Abbaa - father language' among Oromo community. After comprehension of father tongue, the parents initiate counseling children as to identify what is positive and negative in the community circumstance; what type of responsibilities and roles to be played early in life and expected of them in the age group. Counseling steps all members of the family follows may vary from member to member among the community based on certain factors among which the parent's ability to employ indigenous counseling tools is the prime one. But the basic essence is the same since every procedure is in light of the societal rule. Proverbs (mammaaksa) and idiomatic speeches (dubbii haalaa) are the major tools used in counseling that almost all counselors employ in their activities from early life.

Meaning of counseling in local context and its inference: When asked the meaning of counseling and its implication in local context, the elder counselor of Jimma replied that, Counseling is giving assistance to those who need it. It is effective when the community found an individual violating certain rules may call people around and inform us (the leaders) to act on the happening. In such a case elders' advice, and show the individual or group to walk in line with the existing customary systems set by the society. The elder counselor is the one who serves as administrator and lawyer who is in charge of keeping the regulations set by the community and also responsible of generating new customary laws to be established by the community after thorough discussion amongst the society. Here, it seems directive, meditative and preventive than curing after bad situation operates. The determining factor that manipulates all their activity is the rules 'tumaa' imposed by general assembly every eight years. The cultural model of a population serves its members as a guide in their interpretation of events and elements within their universe; it also serves as a guide to their expectations and actions in the universe or environment. The definition given by Ogbu (1990) as cited in Vernon (2000), significantly support the finding of this study stating that, "culture is an understanding that a people have of their universe - social, physical, or both - as well as their understanding of their behavior in that universe." The culture in which the individual lives into and its expectation to life are heavily guided by the larger community which the writer termed as the setting. If the setting is healthy the elements are also healthy in their interactions including all their actions.

The levels or stages of Counseling: Guji discussants revealed that every form of misbehaving and criminal acts will be handled at 'Kontom Daarimuu' (the two main branches of Guji family) where rule and regulations of counseling originate at the general assembly of the community 'Gumi Boko'. Under Guji Oromo considerate, stages of counseling are divided in to three levels to add values of elder counselors namely 'hayyuu' which is to mean knowledgeable. The first level as of all others is family counseling executed by parents, specifically, the 
father. The second level of act upon problematic cases is the kinfolk's level. The upper one (third level) is elite/counselor namely 'hayyu' which are considered as top elites in the group since they are wise in orally capturing the rules and regulations of the community exclusive of any oversight. They additionally put one level to the upper position of using legal enforcing by the law of the community at the level of 'Aba Murti' (judge). Accordingly, as of counselors from Kuyyu, /Aba Kuna/ is the highest level counselor with all its prestige, power and responsibility in the community life who are highly respected among their people. Anything they raise in the course of life is valued as piece of counseling and advice to lead matured life.

How elder counselors join counseling job: Counseling in the indigenous system is gained through appropriate follow-up and attentive look at when predecessors perform it. They learn by carefully attending what has been done and try to facsimile or internalize what is going on. A trainee revise and follow how elders raise probing questions, show patience, loyalty, sympathy, and procedure of attendance, modes of interaction, conformity, community rule and regulations, ethical values and norms, etc. Consequently, respondents confidently replied that they are so interested with the work of parents and devoted to strictly follow what their fathers did sitting under their fathers foot. Willingness, interest, ability to grasp what is going on, memorizing ability of rules of fathers, and enthusiasm one develops in life leads to successful counselor within the community under question as declared by the respondents and belief of the researcher.

As in the other parts of the community, to be Aba Kuna is difficult effort which engross proper training procedures under their predecessors with sturdy enthusiasm for the job amongst the community. To be a counselor in the community settings, the time spent for training, ability to exercise rules of culture, obedience and loyalty, respect to people and rules of custom, exercising the profession as family and kinfolk's counselor at family and local levels are some courses of training in one's own life. If one fails one of the aforementioned areas of assessment, for example, if lacks positive witness of loyalty from relatives, he then stay long for further evaluation until people willingly start putting their cases in front of him for reconciliation or counseling purpose. Hence, individuals entitled of "counselor" position have proper training that is applied in their life circumstances and helping effort to others who may have physical and/or emotional ailments. The counselor's goal here is to help their clients accept their habits or actions that are impeding them and talk about preventative action.

Tulama Oromo leaders elucidated how they join counseling. Being counselor is a gift from God that one's mind should be open to accept and entertain different opinion and views. One should be active listener while sitting under the legs of elders, leaders, and community judges since he is expected to pass through all stages of Gadaa system. Gadaa as a system is the leading Oromo customary administrative structure exercised by the individuals who have the right to take power of ruling in Oromo community. One 'Gadaa' period is eight years that can be transferred to the other 'Aba Gadaa' or leader after eight years of service in the community settings. To become 'Aba Gadaa' or head of the community either to particular locality, for example, Borana or Guji Oromo, you have to pass through certain developmental stages, like 'Dabballee, Foollee, Qondaala, Raaba Doorii, Gadaa' which is equally divided in to eight years of training and exercise based on developmental stages of children in the community.

Although the counselors and/or community leaders 'Aba Gadaa', ordinarily, may or may not read and write, they have strong ability and potential of leading the community in absence of interfering situations from elites, the strange new comers/settlers in and around cities, and political agents. The elders have high curiosity in guiding and sharing life experience to their children in the home, at every minor gatherings when the cattle is back to home (at dusk), working together as support groups 'daboo', in the sentry room of cattle or crops 'godoo' small hut or ' $k$ atila' in which people use as a patrolling room, and on the way walking together to any place: market or neighbor home and in any life continuum in the community. Owing to this reality, every one in the community bestows approbation to the elders. In Oromo culture, older brothers and sisters get respect from younger where they extend curious admiration and value for the elder counselors as well.

In the Oromo community, the leaders 'Aba Gadaa' and the entire society acknowledge and accept the role of counselors and look for counseling services. The license and the procedures or principles of counseling employed all are orally mandated and applied while on the contrary, the Western approach uses written rules gained from legally established body. No deliberation of respect for counselors, no question of role modeling, and no evaluation of counselor's ability in absorbing different challenges exerted from clients among Westerners when assigning trainees to the field of counseling.

Beneficiaries of counseling services: The most common conduct disorder exercised around Jimma which need counselors interventions are theft, violation of rules and murder. Mediating such an act is too difficult for counselor's short term intervention. It needs more time to identify when, how, where, and in what condition the behavior is accomplished. When the counselors entertain cases of the theft and murder, he has to be active in controlling the counseling room environment aggressively to minimize other intruding factors because of the retaliation one exerts on the other.

Elder counselor from Borana firmly underlined that all the members in need of counseling have the right to access the service. Among Borana Oromoo community, the 'kuchuu'/youth/ can travel within the community as 
to exercise different leadership and administrative arrangements. Discussion with elder counselor is one part of their meeting where the ' $k u c h u u$ ' raise significant concerns connected with their stay in the community milieu. Asking clarification for ambiguity which may hinder their voyage is right of the kuchuu done by presenting tambo 'backed tobacco' as a gift for elder counselors since contacting respected person's empty hand is dishonorable in the culture. If anyone from the group faced a problem, he can contact the elder counselor at any moment individually or in a group. Here, the position seems more of guidance than counseling since the youths ' $k u c h u u$ ' get directives as to augment their familiarity and understanding on the way to act in community scenery. This voyage focuses on practicing independent living manner and how they lead peaceful life being with the age category in community state of affairs.

Borana Oromo believes that, prevention is constructive, if one violates rules of the community; and informing the counselor to settle the problem before putting the individual in front of customary court (Aba Murtii) or administration (Aba Gadaa). One best example of this type as mentioned by the elder counselor is an individual who intentionally broke the "hororo '(stick of marriage testimonial or symbol of marriage). This wicked person broke the 'hororo' and put it to fire saying to his wife that 'it is nothing other than a stick used to lit fire'. As a matter of chance, one of their neighbors got to their home and asked the spouse 'why they are talking rudely' in the home, stating that he has heard debate among the spouse while passing besides their house. Then the lady told him (the neighbor) what had happened. The neighbor tries to settle down the dispute chatting with 'Abba mana' (husband) but was not successful. He finally reported the situation to us for interference since he believes that doing such a thing is an implication of disorder in the community culture that needs counseling.

The main issues getting attention according to this finding are behavioral problems one faces in the family, neighborhood and at community level; be it juvenile delinquency, conduct disorder, defiant behavior, offense, emotional disturbance, bullying, family disorders, marriage dispute, violations of established custom and values, theft, forceful marriage (butii), and personality disorders all need counseling support of elder counselors if not resolved at family or kinfolk levels. Minor disturbances, specifically that might has a tie with community rules and regulations get strong attention from all members since it is the concern of the constituent. Other clients are the leading body of the community 'Aba Gadaa' who require counseling when disorder or famine or drought or conflict occurs in their administration. Situations like drought that devastates large geographical locations call for wise consultation of elder counselors developed from life experience and knowledge of facing such inconvenient life scenario.

When disputes arose on boundary among different indigenous community members, the 'Aba Gadaa' administrators discuss with the elder counselors on what to say, do and not to do. Any advice they obtain from the elder counselors paves way to interact, solicit excuse or get in to certain form of negotiation with the community in question. Consequently, if the community they are leading couldn't obey to 'Aba Gadaas' and their administration, they first consult the elder counselors to intercede the situation. Hence, elder counselors are autonomous body to take action against the leaders either by advising them or pass penalty against the ones who fueled the problem in front of the general assembly 'Gumii Gaayyo'. Before endorsing any form of sentence on the leaders, the counselors discuss thoroughly on the issues in a safe place for convincing one another. They can finally call upon general meeting to reach on accepted solutions in front of the assembly. The penalty may be paying oxen or mostly in the form of material pay for the purpose of concluding reconciliation between the leaders and the community.

Indigenous counseling principles: The elder counselors employ well established principles in counseling individuals with problem. The first principle is active listening to the client's problem, helping them express their feelings, wishes, difficulty, and episodes they face in life. The second is asking what they feel, why they come, what they need, what they presume as better and so forth. They raise different probing questions to get intervention points leading to the solution of the difficulty faced. Thirdly, the elder counselor requests to find out why the clients go beyond the two levels of counseling (family and kinship counseling). Fourthly, the clients obtain opportunity of talking and expressing problem encountered in the family or community settings. In this case, the client has got extra time to clearly put his/her view in front of the counselor. What makes this form of talking unique is that, there is no feeling of fear or hesitation about the subject or the counselor in their interaction since the counselors have excellent reputation in the community. Therefore, one can talk whatever feels genuine without any fear since the counselors are only helpers and not fault finders for punishment. Fifthly, the elder counselor is dynamic in finding solution and trying to associate the challenge faced to the existing societal rules and regulations employing life experiences leading to solution. The solution in most cases is what is accepted and believed to be the ultimate result to resolve the problem agreed by the client.

Places of counseling: The Gadaa leaders explicated office used as counseling centers are 'odaa', [green, sycamore tree with massive branch having a shading under which Oromo community sits for praying to 'Waaqaa' (God), where they put the rules and regulations into effect that govern the society; where an oath is deliberated not to violate the covenant 'tumaa'; where elders counselors or 'Aba Gadaa' give imperative decisions regarding the community; where individuals with criminal acts and other allegations were judged]. Gadaa Melba (1988) invoiced 
place of Oromo Chaffe assembly as was held in the open air in a meadow under the odaa (sycamore) tree. The chaffe made and declared common laws and was source of the accumulated legal knowledge and customs'.

Other places are the 'Godoo' separate small hut primed for recreation and can serve as a counseling room near the big house or individual's home (either of the client, family or neighbor house). The 'tulluu' plateau or mountainous place which is regarded as sacred location especially identified for place of discussion, worship and prayer among Oromo community are places where elder counselors conduct the counseling. These places are where elder counselor conducts the counseling services though the situation under counseling necessitates where to handle it. Cases which involve groups of people need out of home situations while individual cases were most likely accomplished around home settings.

Steps and approaches of counseling: When asked what makes indigenous counseling system special of its character, Borana counselor replied that indigenous counseling is characterized by free offering of something to eat and drink since it is unusual in the culture of Oromo community to leave a guest coming to one's home without eating or drinking from personal belongings. This form of invitation makes the client to relax and speak apiece of predicament coming to his/her mind, since all the clients believe that friendship and mutual understanding is established. Hence, positive rapport is conveyed during the invitation carried out in the counselor's home. Additionally, straightforward conversation that seems irrelevant to the client but intentionally set by the elder counselor may be presented during the meal or coffee ceremony that might assist in minimizing the tension the client may experience. It is best approach to rapport with the clients if he/she is new to the counseling relations. Once clients get in to discussion, they continue on the matter after coffee ceremony without apprehension about the counselor and conditions faced since the talking is continuation of the informal session.

The counselor is of resourceful mind to react, pose questions and carefully respond to the query posed by the client. What is evident among Oromo community before decades is the trustworthiness one has on his community rules of life. No cunning to one another and towards the counselors' questions. But, the younger generations, as of the Kuyyu Oromo counselor's belief, happen to be disinclined to abide to the rule of fathers and keeping their integrity in social relations. Kuyyu counselor continued stating that, the intrusion of alien religion, superficial knowledge of modernity, inappropriate curriculum that didn't consider culture of the indigenous and cultural mystification of the new comers from neighboring community highly affected the culture young generation inherited from the fore parents made indigenous counseling more smashed and elapsed.

Time bestowed on counseling: This finding reveals that the time spent on counseling varies depending on the issue under deliberation. Minor cases like behavior, emotional, personal disputes (family), delinquency and mood related disorders are obviously short. But, disputes between clan, ethnic conflict, theft (cattle, crop ...), looting, 'butii' (forceful marriage), breaking rules of the community and insult of group/clan/society. A counselor from Jimma discussed on how long they involve on counseling or hours they stay on each sessions. The time bestowed on family counseling is the same for all localities as of the case vary from individual family hold to the other. Counseling for family members may take longer period in a day, but might not exceed the given day; because, issue of the family has to get solution immediately. If it goes beyond a given day there is a belief or community saying that passing a night differently entails difference in heart or relation 'nama halkan adda bule lapheetu gargar bula' which specifically refers to spouses. This and other coercing factors press the elder counselor or kinfolk counselor to settle family disputes and difficulties within a given day, devote all their time and capability, the whole day. This reveals that elder counselors give great attention to peace and security of their community than their own choir. Counseling deliberation in the indigenous treatment didn't give focus on the time than accomplishment of interventions, smoothening of conditions and instituting collective security.

Counseling techniques and rules employed in service: The principle, techniques and methods the counselors employ were discussed subsequently. The underlying technique employed by the counselors is derived from community assembly 'yaa'ii sabaa' (Jimma), 'Gumii Gaayyoo' (Borana) and 'Gumii Bokkoo' (Guji) embarked earlier than the community leader 'Abba Gadaa' leave his power to the new administrator.

Techniques of counseling are of varied type where counselors can swith the system depending on the client's problem. The major techniques are: through singing 'sirba', use of proverbs 'mammaaksa', hymn 'weedduu', by tracing to or characterization or using others experience as role models; employing myths or epic tale of the past 'baacoo', etc. The techniques in use were narrated by community assembly and the elder counselors strictly follow these customary rules and regulations forwarded every eight years by 'Gumi Gayo' (community assembly), agents responsible announcing all the law that the community should stand for. If anyone didn't accept what is suggested or withdraw all the options stated, he/she is automatically cast off from the society as of the rule publicized in the institution. But counselors will strive convincing the client until reaching on conformity.

\section{Discussions}

Counseling is perceived as helping individual to identify what is useful and not, teaching, advising, directing, guiding, teaching rule of fathers, interacting and communicating for better life as of Oromo community. It is more of preventive and teaching than helping after getting in to difficult circumstance. It is related with treatment of 
daily life condition of members as guide to proper life style accepted among the community. Oromia Index Bulletin (2008), support the portrayal of this study result stating that, "treatment of everyday problems is more often referred to as counseling (a distinction originally adopted by Carl Rogers) but the term is sometimes used interchangeably with psychotherapy".

Counseling among Oromo community in Ethiopia is a tradition communicated from generation to generation attaching itself with Gadaa administrative system. The general guidelines and system of counseling embed in the rules and regulations of community custom. Gadaa Melba (1998) indicated that "in the Gadaa system of the Oromo people, the cradle of biological as well as cultural civilizations of the human practices and teachings transferred from one to the next generations from time immemorial that man-made laws are treated as the product of human endeavor and deliberation invented by great law makers." Thus, the genius of Oromo's, the master of law makers does not consider it as a gift of God or heroic ancestors or as supernatural thus incontestable. In addition to counseling services evident in the community, elder counselors are best examples in their performance and elegance. The community (children, adolescents, adults) learn from what the elder counselors do, act and execute in the community context. That's why, counselors are so careful in performance, interaction, and maintaining appropriate life style in their walk and way of life. They are perceived as role models in every facet of relationships as to advice and counsel community leaders (Aba Gadaa) in order of balancing truth and reality. Dissimilar to this finding, Vontress (2001) agreed that in the Western societies in particular, "the counselor is anyone, male or female of any age, who has met the academic preparation requirements, set by the state or some other jurisdiction. But, the study result of this research underlined that academic performance is not the only criteria leading to counselor position even though the researcher on no account opposes the value of formal training and education.

In the communal society of Oromo culture, there was/is no lie, no pretension, no cheating of thoughts and property, no defiance, no prejudice and unlawful acts. If an individual commits any form of disobedience or violation of certain rules, he directly goes to the elders locally or community counselors to ask excuse with full repentance. During these periods, as of the explanation of Gadaa leaders, there was peace and love among the community. No destruction, no turmoil, no chaos, no starvation, no quarrelsome, and no tribulation within the community settings except simple conflict with other ethnic groups on boarders that can be easily resolved by the intervention of community elders from both sides. Due to this fact, there were no as such significant problems that may go beyond the family and kinfolk counseling level. The study conducted by Raymond and Richmond (2008) strongly support this finding implying that "as long as you generally adhere to the law of the culture in which you live, and if you are satisfied with your life, then there is no problem and no need for prying."

Very few cases reach elder counselors with regard to the problem or difficulties one faces in his life. But counseling for the developing children is an inevitable fact at all levels of developmental stages among the community as a tradition. Hence, this study revealed that beneficiaries of indigenous counseling are the community at large who needs assistance anytime. Growing children, marriage couples, the one disturbed, individual in stressful situation/confusion get the service without any payment. Individuals in interrelationship conflict may also request interference of elder counselors as to resolve the incongruity. In support of this study, Pelling and Sulivan stated in their book of 'The credentialing of counseling in Australia', "populations served by counseling psychologists include persons of all ages and cultural backgrounds" (Pelling \& Sullivan, 2006). One can therefore, simply identify that any problem raised as individual case (behavioral, emotional, personal, social, political, cultural and others) could appear in front of the elder counselor if not get resolved at the lower binary sessions. Anyone with problem can communicate the counselor for service. Parents or spouse of the problem person may demand the counselor for assistance representing the individual. Relatives or neighbor also may ask for counselor's intervention if he/she assumes relevant and proper as to decrease risk factors arising from problem person.

Being interested and potentially well-equipped in the profession, loyalty, acceptance in the community, ability to entertain different views, narration of counseling rules, respecting community guidelines, generosity, honesty and genuineness is the underlying poise considered besides education (formal or informal). Similarly, Pelling and Sullivan (2006) comprehended that "counseling psychologists adhere to the standards and ethics established by the American Psychological Association and the American Counseling Association". Alternatively, ability to cultivate traditional rules and customs relevant in keeping an individual in the expected and accepted way of life needs life experience than education. Respecting others, hold anger of clients with patience during transference (as of psychoanalysis), sense of being exemplary in the society through performance, ability utilize diverse life instances, use of terminologies free of social taboo, skill of cultivating societal imperatives and employing locally developed techniques are relevant issues considered in the counseling approach of Oromo community. It is evident that certain requirements like counseling skills, being licensed and knowledge of the community custom are fundamental in any counseling act. Nevertheless, integrating knowledge of the Western counseling system to the culture based techniques and methods used in the community settings are central in the employment of indigenous counseling approaches.

All developmental stages have identified purposes to be performed by the group as set forth by the community 
which needs further study. In doing so, to become a counselor, one has to be respectful, loyal, famous, not accused of any crime in the community; impartial, who has passed through rituals and community practices, and free from any form of transgression in the community. Sitting under elders and parents feet to listen to what has been said, being alert to concentrate, being brilliant to catch-up all the things practiced, role play among peer, and acceptance of peer and elders to rely on what one is intended to act are some determining factors in addition to the aforementioned points. Passing in to such and other forms of community undertakings, one becomes area counselor in the locality. After being local counselor for longer period and being evaluated by the community in general who can be nominated or got acceptance as elder counselor at the larger community context. Nomination is mostly done in the course of community preference and interest to go to the preferred counselor for assistance based on the choice.

There are differences between indigenous and Western counseling practices among which few are presented below:

- The elder counselor is the only teacher or trainer who is responsible giving all courses, coaching and evaluating the student on practical activities. On the contrary, the Western counseling education is given by professionals certified in different disciplines of psychology and counseling. Wampold (2001) strongly support the result of this study as "Psychotherapists are often trained, certified, and licensed, with a range of different certifications and licensing requirements in every jurisdiction."

- The learner under indigenous counseling joins the field with interest and great enthusiasm to assist people than anticipating benefit or payment from clients. Therefore, he is keen to benefit the community exclusive of any profit in cash or in kind. In return, the community willfully is responsible assisting family of the counselors in every life affairs without any notice. Conversely, counseling in Western society is scheduled as per the benefit counselors obtain from clients after service provisions. It is a field of survival stepped to open job opportunity to the learner as to make money. In accordance with this finding Wampold (2001) enlighten that "Psychotherapists usually receive a benefit or remuneration in some form in return for their time and skills."

- Indigenous counseling systems is most preferred field of choice for the trainees with a dedication to societal wisdom and memorizing ability of rules and regulations executed by community assembly either by hearing from elder counselors or participating on the meeting. In the Western counseling system, a student with a good score can join counseling profession without familiarity to the rules of society. Correspondingly, according to Wilgosh and Gibson (1994), to react successfully to the culturally diverse world community of today, the counseling profession must develop skills and knowledge related to communicating with clients from a variety of national and cultural backgrounds, understanding their specific needs, and assisting them to find solutions to what are often culture-specific problems.

- Knowledge of societal culture is another abiding criterion to be a counselor in the indigenous counseling system. The respect, value, ethics, norm, taboo, custom, way of life, rules of conduct, rules of people and animals, and others are critical areas of attention that elder counselors consider in their assessment of training the successor. On the contrary, these all cultural considerate are overlooked by western counseling systems.

- Since indigenous counseling system relies on practical training, question of keeping confidentiality is an asset in the learning. Accuracy of performance, complying with the counselor, ability to persuade age mate, and humbleness to client are compulsory features of the trainee's survival in the field. But in the western counseling system, academic performance is the only appraisal expected from the individual to complete course of the study than giving critical consideration to the culture (language, interaction, taboo, significance ...) of the client.

- Teaching in the indigenous context is practicing every matter in afresh form being a member in the community settings. On the other hand, in the western counseling style, training is loosely connected to entertain community culture and language and almost ended in the Institutional location. What counselors learn in the schools is almost ready made that relies on the past events, methods, techniques, theories and schools of taught. In connection to this finding Turner-Essel and Waehler (2009), states that "many counseling psychologists in the United States still lack awareness of international developments within the field".

- Even though behavioral manifestations of individuals might have universality and curriculum of counseling psychology is almost similar globally; performances of manners possibly will vary critically from culture to culture based on the environment and culture of the individual where he/she was brought up. This in turn has great impact on the courses designed which needs adaptation and flexibility to capture culture based differences. Because, as stated by Laungani (2005), "our ideas, approaches, techniques, values, methodologies are to a very large extent influenced by our culture and the dominant epistemology (or epistemologies) to which we subscribe". This study result revealed that areas of behavioral characteristics unique to different cultures need further study. 
- The trainee, being with the elder counselor, is able to devise certain methods useful to tackle certain problems even if the overall abiding rule is there. There is a room for flexibility if the method devised is efficiently operating contrary to the western counseling systems which are seemingly rigid.

- Based on the question of its source, counseling practice totally belongs to the society where every member of the community has contribution in its enactment. Conversely, the western counseling system is based on personal philosophies and theories narrated by individuals like Freud, Rogers, J.B. Watson, Kohlberg and others. This philosophy may or may not apply to all individuals while in the indigenous counseling approaches the methods followed and techniques employed are aggregate views of the community than of sole property to one individual or one school of taught.

- Training under indigenous counseling system is totally field oriented and practical in nature while training under the western system is mostly classroom dominated and bookish. There is no need of training manual, books or reference citation in indigenous counseling modes of training. In fact, the writer is not negating availability of books, written documents and references but being bookish or book knowledge alone couldn't determine what one has possessed and devotion of counselor in serving the community.

Keeping privacy and being confidential for individuals opinion is one of the underlying ethics considered by the counselors. If the situation of counseling is between family and groups, the counselor is not accused of insecurity or confidentiality predicament. In support of this finding, Yusuf (1977) noted that 'the counselor or therapist provides a setting of safety, confidentiality, acceptance and concern that allows clients to explore their issues more fully and to find new ways of approaching them."

The finding of this study make known that counseling administered for family or groups of people (may be clan) is conducted on open spaces under sycamore tree, or plateau or around chaffe (wet land). It is also possible to conduct counseling for groups gathered together for different purposes which is said to be group or mass counseling. Accordingly, counseling service is open to all members of the community irrespective of sex, wealth, misconduct, crime, disobedience, or education. In areas where elder counselors are not member of Gadaa council, they can even advice 'Aba Gadaas' either by going to their home or call them to their residence. In this regard the leaders respect these elder counselors since they believe that they have rich life practice and able to counsel them.

The steps followed by all elder counselors are almost the same since the order starts from arrival of client to the counselors' home. Inviting the client to home augmented by invitation to drink coffee is familiar in the culture of Oromo community. Informal discussion continued with the client on the coffee ceremony. If the client's problem needs privacy, he can share the situation to the counselee where they may talk alone. The counselor immediately changes the conversation until they finish the coffee ceremony and take safe place with the client for discussion. The client might reach on conclusion with the assistance of the counselor or have an appointment for the next session.

As indicated in all the results part, one cannot easily put standardized rules of move in the indigenous counseling system since there are/were no written documents to follow. Whatever transferred from parents to children may face distortion or modification that makes certain differences in the same community with different geographical locations even if the procedures are nearly similar. The techniques or methods employed are also the same. In the areas covered under this study, the methods used are of varied type, involved lofty tolerance in client care and support, worthy self devotion to serve the community, preservation and intact culture of respect to human creature with full of deference 'safuu' to God. On the contrary, certain areas of the west and eastern part of the region were invaded by new and alien religions; settlers of other regions and urbanization breakthrough to the indigenous culture of community which impeded 'safuu' the respect to creator and creature.

Likewise, reinstatements of community customary rules get polished every eight years. Eight years represent one delegate of 'Gadaa' administration before he passes on the 'bokkuu' (string of ruler) to the new one who is going to succeed him. Arnott underlined practices under Gadaa admin stating "under Gadaa, every eight years, the Oromo would hold a popular assembly called the Gumi Gayo, where laws were established for the following eight years. A democratically elected leader, the Abba Gadaa, presided over the system for an eight-year term (Arnott, 1993)."Once the rules were established, the counselors become responsible to apply the newly added statutes in their work of intervention in maintaining peaceful way of life within and among the community. The elder counselors have ability to recall most of the rules endorsed by the community in their career which adds salient respect on them from community, including youth, adults and the aged. They are 'walking computers' in the community able to retrieve what is sanctioned on the general assembly. As a result, the elder counselors are referred as judges using counseling terminologies as a directive in showing what is permissible in life and illegitimate vis-à-vis unacceptable once in the culture.

All oral rituals passed on 'Gumi Gayo' thorough discussion between community congresses is the guiding principle counselors employ in their work. If an individual deliberately violates rule of the society, he or she may flee to other locality isolated from the public or ask forgiveness to return back to the community. The punishment aligned with intentional misbehaving acts next to corporal punishment (in former times) or disobedience is total 
prohibition including wedding and funeral ceremony, impede talk or walk with, not raise herds with, no support if requests, and may be total ban. The fate of such disobedient person is fleeing to towns or get in to foreign religious acts that disregard community institution. Since the one who violates community norm is disregarded by the community, no one dares to contravene the rules; because, he (the one with problem) is part of the congress that enforces the law involving on 'Gumi Gayo'.

Since the course of action counselors employ emanates from the rules commended by 'Gumi Gayo', it is considered as part of general rule and regulation of the community. Accordingly, methods used in the counseling may vary depending on the challenge encountered. What so ever the case may be, the evident and major techniques/methods of counseling prevalent in the community are the following.

- 'Mammaaksa' (proverb) - is one best technique employed by all members of the community to guide, direct, advise, counsel, warn, correct, or teach an individual in the course of life. There are proverbs of counseling that has great value in the individuals thought able to examine ones way of life. It serves as a mirror in which one can evaluates himself, inspect his did or act, examine his way, take scrutiny of his emotion as compared to the rules and regulations of the community, and may regain consciousness in the realm of the stated societal decree. The community poses proverbs before, in middle and at the conclusion of every conversation whenever suppose essential. Proverb is used on individual converse, group interactions, debates and so else. This area and how the community employs proverb are open for further study.

- Songs 'sirba'- counseling in the form of song used in Afan Oromo are said to be of double meaning presumed as idiomatic in nature. It is composed of phrases that have binary meaning on the second phrase having rhyme. It has easily understood meaning and hidden meanings in the phrases. This form of song is of divergent type like song for oxen during plowing or herding cows, wedding, festivity, holydays, cultural rituals, and gatherings.

- 'Mararoo' is another form of song used to grant final advice for the girl on her wedding ceremony. When all things are ready and confirmed that the lady (bride) is going to leave home, her girlfriends chant 'mararoo' as a last statement of saying bye to their friend so as to lend a hand for the lady fusion to new family. It is word of strengthening her for future life which could be challenging one in the union. Parents also get convinced because of the loss of their daughter to strange area and house through Mararoo. It is exclusively used as a heart touching advice that makes an individual to think and rethink of "what has been said' in ones connection of mingled life; most likely, when faces challenging situations in ones journey of life. Mararoo is a statement of attention among the community when used as finalization of all relations or winding up of discussion in anticipation of what to happen. It has influencing power to alter decision of an individual whether one chooses positive or negative route in balancing the new and old life.

- A hymn 'weedduu' is almost similar to that of song 'sirbaa' but limited to individual's ability comprehending the statements in the way that it is sweet for the listener and has manipulating message. It is mostly used for herding and counseling purpose exploited interchangeably with proverbs, idioms and song. It has the ability to attract attention of people in the sense that it can serve as teaching and counseling with sweet melody. The researcher believes that it could be potential area to be studied as folklore of Oromo.

- 'Baacoo' is counseling method using narration of oral folktales /epics/ in the real world to teach, entertain, direct and guide one on constructive course of life. It has massage to life circumstances combining the history in the folktale with personal life to adjust in the way expected of an individual. The person in front of the counselor (family or kinfolk or elder counselor) evaluates his character in relation to the tales, seemingly organized to remind you of the real life, and assist to reposition in the way the community expects. Baacoo is presumed as one of the best techniques of counseling, exclusively in teaching people, irrespective of certain differences based on geographical disparities.

- 'Geerarsa' - is form of folksong one explains himself as brave, worrier, express feelings of sorrow, happiness like birth of a son in the family, show courses of action in faacing challenging circumstances, etc. It is oratory vocalizations in the form of song to win hearts of the listener or trying to touch deep feeling of an individual in the sense that the singer 'geeraraa' can divert thought of the distressed through intricate terminologies of 'geerarsaa'. The manner it is presented, statements in the folksong, and the voicing (rhythm) has sturdy impression to comply willingly with singer's interest forgetting challenging and complicated situation. To this end, individuals with mental illness also give attention to this form of folksong if not severe state since it has strong power to draw attention of the listener as it was designed. Wherefore, it is termed as best form of inspirational counseling among Oromo community and other community members of Ethiopian ethnic diversities. Geerarsaa, moreover, has power of stimulating, motivating, and touching the affective mood of an individual calling for all good things of the kinfolk, or initiate for acting or show direction of performing things. It is a form of probing, initiating, and 
motivating method in the indigenous counseling system. Therefore, counselors use this method as motivational approach and intervention technique, particularly, if the individual is of hidden type or didn't want disclosing about his problem in front of the counselor.

- 'Jechama' is assumed as idiomatic phrases used among Oromo community. Instead of using four or five statements, one can use very few words, most probably phrases to awaken the problem person or make him alert. When the counselor uses 'jechamaa' in his conversation, the problem person institutes to think and rethink of the meaning with hidden connotation. The problem person starts to navigate his mind 'why the counselor uses such a phrase' in this session. If the client reaches on certain form of conclusion or develop insight, he can respond to the counselor in a way that he is on the right truck. If unable to associate or recall the actuality, he has the right to request for the implication. If he believes, the phrases are irrelevant to his own problem, can explain his feeling in different way as to clarify his personal challenges and difficulties. This form of counseling facilitates mutual understanding between the two.

- 'Cooka' also choka - is used to treat individuals with mutistic behavioral disorder, dullness, annihilated, and who goes through failed mood disorder like distress, withdrawal, shyness, loneliness, etc. This technique is similar to that of 'geerarsaa' which instigates and arouses mind of the patients and awaken from daunting mood which assist them to get into interaction with human beings. At this moment, the elder counselors aggressively follow the mood changes observed on the client to decide and proceed or change their techniques. If the individual is stirred up and show awakening up of his disorder, they proceed to the next level with the assistance of elder counselor to participate in the play 'choka' taking a turn. This technique is employed if the problem person can perform activities taking a turn either exaggerating the family and ancestors: calling his father, grand fathers and/or tribe. The elder counselor is responsible deciding what to do next depending on whether the client get inspired or continue in his/her distress.

- Role playing - is used as follow a person with good behavior, well known personality, exemplary of good relation and models of good practices in the community. These models are seen as prominent figures in the society. In the counseling sessions, elder counselors use those outstanding peoples as important personalities and role model for these new generations, specifically for the one who is in challenging incidents. The one who is in a problem and/or growing children are guided to follow these model personalities in their life, as much as possible, to endure the phases of challenging world. Children or individual with problem are directed to role play looking to the role models as taught by the counselors. In this activity, parents are the best role models for children while prominent figures of Oromo community become evident role models for youth and adults in different Gadaa grades.

\section{Conclusions and Way Forward}

Counseling is a method of resolving personal or emotional problems through a special form of talking made between counselor or coach and the client. It assists to reflect to the situations one encountered in through assistance of experienced or professionals to get to solutions from personal distress, poor relationship or difficulties through accurate listening and talk. Counseling is a course of life among Oromo community since it begins right from the date of birth through developmental periods though the amount bestowed on the coaching may vary depending on the age and the situation one may encountered.

Counselors are trained sitting under the footstep of elders participating on the same services while professionals in the field of psychology and counseling are those who are assigned to the field based on their personal interest or forced to join the field, specifically in Ethiopian Higher Education systems. Contrary to the Western system, indigenous counseling is understood in the sense of teaching, guiding, directing, advising, coaching, and assisting guided by customary rules and regulations pertinent to the community. The researcher believes that everything that emanates from the community and serving the community has to take its reference to the promoters themselves; i.e., the community. Accordingly, the following are assumptions developed from the findings.

Assumption I: Indigenous counselors presuppose counseling as an asset of the community that emanates from the society and designed to serve the community than considering as profession. It as indigenous knowledge and skill applied in the community context than assuming as personal talent or philosophy. The skill gained is attribute of the community like child rearing practices, community rituals, Gadaa administration, 'Qaalluu ' (wise) and wisdom like Oromo calendar which is rooted in lunar system. Hence, the elder counselors are regarded as respected and wise people born with brilliant capability to serve the community without negotiation of service charges. And sense of belongingness is key disposition of the elder counselors. Hence, Oromo Community understood indigenous counselors as elders, kinfolks and parents of any individual in trouble.

Assumption II: Counseling is life practice for Oromo community though, no one could portray when it was introduced in the public. But, the society reveals that counseling is a culture in the community serving as central tool in maintaining ones need with respect to the societal interest or the group in which the individual resides. 
Since counseling is an institution for Oromo community, there could be a need to organize counseling techniques, concepts and methods based on indigenous knowledge side by side to the modern counseling systems adapting to fit to the local circumstances.

Assumption III: Indigenous counseling methods of Oromo community rely on mutual understanding and sharing opinions between the counselor and the client/s. It is an interaction made amid the client or relatives or caregivers or parents and the elder counselor or kinfolk's counselor. At early ages, counseling is handled by parents at home level sustained by kinfolk's and elder counselors focusing on rules and regulations of Oromo community executed on general assembly. Hence,

Assumption IV: Oromo community gives great attention to their children since they believe that children are gift of God 'kennaa Waaqaa' and they are responsible to rear them in the way that it is acceptable to the creature and the society at large. 'Safuu' and 'dudhaa' are principles children learn from parents. If you say that 'safuu qaba!' it means, 'it is a taboo' taken as inviolable and/or respected in the community settings. Therefore, children learn 'safuu' and 'seexaa' (feeling of accomplishment/success/ or having desired goal) at home from family, elders and community leaders within the community scenario.

Assumption $V$ - Indigenous counseling is lifelong activity that starts at birth after knowledge of father tongue 'Afaan Abbaa' and carry on up to old age. Adolescent counseling is continuation of child counseling that could advance to adult and old stage of development. Hence, all members of the community need counseling support anywhere (in specified place, under sycamore tree, on the way ...) and all the time.

Assumption VI - In indigenous counseling system, a trainee with a vision, enthusiasm, determination and interest to assist people is assigned to attend training at a time. The time bestowed on the training varies depending on the potential, capability and understanding capacity of the trainee which may require more than couples of years, mostly from five to ten years following footsteps of Oromo elites 'hayyuu'. This period is time to study all the rules and regulations of the community used in counseling and practice the processes, procedures, techniques and principles of counseling.

Assumption VII - Indigenous counseling is characterized by preventive approach of counseling to stabilize and maintain peace and security among the local citizens. It is exceedingly effective in minimizing risk factors of behavioral, emotional, social, political and economic challenges before it emerge. Most of the counseling levels, types and methods were exclusively employing preventive counseling at home, group and community levels that works out among Oromo community and adjacent civic associates of Ethiopia. The ultimate goal of indigenous counseling is teaching, guiding, directing and showing direction for growing children not to involve in bad acts, crime, misbehavior, extravagancies, unwanted interactions and unacceptable did that may hamper their relationship and life within the community sceneries.

\section{The Way forward}

Types of counseling applicable within the community endorsed by the author are the following:

- 'Gorsa Maatii' (Counseling at home/family/ level) - this type is conducted at home where parents tell, teach, advice and guide their children practicing certain lifestyles within the community perspectives. The father as head of the house, accomplish the responsibility of directing his children as to perform certain activities suitable to the age group, respect rule of parents and elders, track rules and regulations of the society, perform tasks planned, keep taboo (safuu) and rule of relationship (duudhaa) of the community; being brave in defending self from attack exerted from animals or human robbers, or alien intrusion, etc. The counseling is continuous till the child reaches age of adolescence directed by the parents. Because of this, every parent needs his child to resemble him as much as possible in respecting and abiding to the rules of fathers in all spheres of life. Hence, the parents are role models for their children in the course of childhood life designated as home counseling.

- 'Gorsa Kuchuu' (Adolescent counseling) - this form of counseling focuses on youths of the same group when pulled together in search of elder counselors for counseling willpower. The 'kuchuu' adolescents of the age $16-24$ considered bearing responsibility by making pilgrim in the community environment which is common for Borana, Guji Oromo and adjacent area Oromo community. In other areas of Oromia like 'Liban', elder counselors and Gada leaders take the responsibility to bring together adolescent of the same age groups equivalent to 'Raabaa', to take responsibility from parents. It is critical time when discussing how to establish home since it precedes marriage stage. 'Kuchu' is a stage social stratum where one learns how to use money, lead life independently, and time to accomplish all errands of leading, feeding, guiding, and overseeing the younger siblings. It is grace period when they acquire and put into effect custom related personal and social accountabilities at individual and group being with elder counselors. The ample time granted to exercise leadership role among the group in the course of 'kuchu' pilgrim assists them in taking initiatives to communicate with elder counselors, Gadaa leaders, model family heads and opportunity participating on community gatherings. They also can hear the rules and regulations executed on community assembly as best life practice. 
- 'Gorsa dalagaa irraa' - on the job counseling is another form of group or individual counseling conducted for the purpose of personal development. It involves how to save property, give tenable value to work, usefulness of group works like 'daboo', 'daadoo', jigii, 'tumsaa', 'labbuutee' (all are different forms of communal work to support one another) and others in the community settings. Its relevance and usefulness is admired using proverb and poems, oral literatures, narratives and 'baacoo' (a folktale type of teaching through narrations of events). The community habitually practices collective work support groups to assist the weak, community leaders (Aba Gadaa, elder counselors, the old and the widowed). This mode of counseling includes training phase where a trainee practice and workout in the session.

- 'Gorsa bu'uuraa' - Critical counseling is another form of counseling evident when an individual faces a problems in life. If one is suspected of stealing property in Jimma and Kuyyu zones, people may suspect of the person involved in criminal acts. And the individual committed the crime needs critical counseling on the prevailing offense. This counseling technique employs evidence of suspect in front of the neighboring community meeting. It is precise to single problem array where the individual is instructed not to participate in such objectionable act if admitting his wrong did. The individual may be singled out (saaxiluu) in front of the 'yaa 'ii' (bordering assembly/gathering) for the crime done if not admitting. The individual is responsible to compensate for the property he has taken off or stolen in either of the cases. The counseling contributes in protecting the problem person not to get in to grief and tension referring to society rules and regulations. After proper counseling sessions, the individual asks the assembly to excuse him via the help of elder counselors as to attain thought emancipation from the misconducts and wrong performances.

- 'Gorsa gaa'ilaa' - Marriage counseling begins earlier to the age of adolescence aided by the mother for female and father for the male before they get into any form of opposite sex relation and cultural dancing (sirba). Before foreign cultural diffusion to Oromo community, the Oromo girls, under no circumstances get in to sexual practice before marriage. But, s/he might have lip lover or make a kiss with male/female lover which is equivalent to current boy/girlfriend. Both adolescents obtain apposite advice and counseling from their peer group and family on beauty, work, respect, honesty, loyalty and relationship. Intensive and profound counseling lingers by parents, kinfolk and elder counselors during engagement up to marriage conclusion. The other version of marriage counseling appears at all three stages (pre, while and post) if any form of argument occurred between couples or marriage partners.

- 'Gorsa garee' (Group counseling) - is sometimes called as family counseling in which people of the same category get counseling service headed by elder counselors or 'Gadaa' leaders when problem arises between family members or individuals from extended family connects like grandfather/mother with their numbers of married children living together in a gather. At this moment, the groups need counseling services either because of disagreement among the family members or conflict between ethnic groups or due to violation of customary rules. Whatever the case may be, the groups receive counseling on common ground. The counseling may be initiated by any member of the family or community to the elder counselors or Gadaa leaders.

- 'Gorsa hiriyyaa' Peer counseling - is common right from peer selection phase at early childhood level. Children exercise what they have observed from family on meal, when collecting cattle, during group work 'daboo' or 'jigii', and while sitting to heat fire. They rehearse peer counseling whilst playing together, looking after cattle, exercise parenting play or act (father - mother role play), at pilgrim during the years of 'kuchuu' and schools. Peer counseling is sometimes assisted by strong follow up of kinfolk and elder counselors. A child who plays leading character could possess counselor position with persuasive potential if fulfilled other criteria. But, recommendation from a counselor is of primary importance. The same applies for age levels (gaammee according to Gadaa Malbaa) leadership in peace and security, Gadaa labor divisions; and collective gathering.

- 'Gorsa eeruu (Trace counseling) - is another form of counseling given by analyzing situation of particular individuals or groups. It is prearranged, in most cases, for members of similar age group, to minimize challenging forecast of bad fortune or interference of external acts like religious, political, cultural invasions or natural horrific disasters. Community members become alert if they get appropriate advice and counseling on the forecasted state of affairs. It is a form of warning sign or revelation by 'ayyantuu' or 'qaalluu' to aware the community not to be confused after the occurrences happen from nature or human calamities targeted towards a given age level or community.

\section{Acknowledgement}

The first and foremost appreciation goes to the elder counselors and Gadaa leaders involved in this study who keenly gave me rewarding information. My grateful appreciation also goes to Jimma University for their financial assistance. 


\section{Research gaps identified}

Different parameters and concepts of indigenous counseling were left us research areas for further study among which Oromo knowledge systems like safuu, duudhaa, ayyaantuu, qaalluu and Gadaa grades considered as major ones. 'Safuu' (word of respect) known as Oromo wisdom which needs further study with its broader analysis on how to manage and exercise societal rules from micro to macro stage functioning among the community.

\section{Limitations}

This research undertaking only employed qualitative research and five zones of Oromia where other regions with ethnic diversity in the country were not included to focus on multicultural aspect of counseling.

\section{References}

Abdul Basit (2005). Principles of Counseling. Department of Psychiatry, University of Chicago - Prtizker School of Medicine

Arnott (1993). Bull leaping as initiation ritual. Liverpool classical monthly 18

Asafa Jalata (2012). Gadaa (Oromo Democracy): An Example of Classical African Civilization. The Journal of Pan African Studies, vol.5, no.1

Corbin, J. (1986) Coding, writing memos, and diagramming, in From Practice to Grounded Theory, (eds W.C. Chenitz and J.M. Swanson), Addison-Wesley, Menlo Park, CA

Gadaa Melba (1988). Oromia: An Introduction to Gadaa System - Khartoum, Sudan

Given, L. (Ed.) 2008. The Sage encyclopedia of qualitative research methods. Sage Publications.

https://en.wikipedia.org/wiki/Counseling psychology (retrieved, November 2008)

Johnson, M. (1992). Lore: Capturing traditional environmental knowledge. Ottawa, Ontario: Dene Cultural Institute, International Development Research Center.

Laungani, P. (2005). Building Multicultural Counseling Bridges: The Holy Grail or a Poisoned Chalice? University of Toronto.

Nsamenang, A. (2007). Origins and development of scientific psychology in Afrique Noire. In M.J. St evens and D. Wedding (Eds.), under the supervision of John G. Adair. Psychology: IUPsyS Global Resource (Edition 2007). London: Psychology Press. http://www.psypress.com/iupsys/contents.asp

Nsamenang, A. \& Dawes, A. (1998). Developmental psychology as political psychology in sub-Saharan Africa: The challenge of Africanisation. Applied Psychology: An International Review, 47, 73-87.

Nsamenang, A. \& Lamb, M. (1995). The force of beliefs: How the parental values of the Nso of Northwest Cameroon shape children's progress towards adult models. Journal of Applied Developmental Psychology

Oromia index Bulletin (2007). The Legend of Akkoo Manooyyee. http://www.oromoindex.com/forums/showthread.php?8812-The-legend-of-Akkoo-Manooyyee

Oromo Religion: http://www.geocities.com/Heartland/Fields/2379/oreligion.html retrieved 24/03/2000

Pelling, N. Sullivan, B. (2006). The credentialing of Counseling in Australia. International Journal of

Perez, F. (1965). Counseling: Theory and practice. Reading, MA: Addison-Wesley.

Raymond Lloyd Richmond (2008). A Guide to Psychology and its Practice. http://www.guidetopsychology.com/index.html, San Francisco, California USA

Rogers, C. (1961). Client-centered therapy. Boston: Houghton-Mifflin.

Sinha, D. (1990). Interventions for development out of poverty. In R. Brislim. (Ed), Applied Cross-cultural Psychology, 77-97. Newbury, CA:Sage.

Turner-Essel L. and Waehler C. (2009). Integrating Internationalization in Counseling Psychology Training Programs. SAGE

Vontress, C. (2001). Culture and Counseling: A Casebook. George Washington University, U.S.A.

Vernon, P.E. (2000). The Structure of Human Abilities. London: Methuen,

Wampold, B. (2001). The Great Psychotherapy Debate. New Jersey: Lawrence Erlbaum.

Wemlinger, C. (2008). Identity in Ethiopia: The Oromo from the $16^{\text {th }}$ to the $19^{\text {th }}$ Century. Washington

Wilgosh, L. \&. Gibson, J. T. (1994). International Journal for the Advancement of Counseling 17: 59-70, Kluwer Academic Publishers, the Netherlands.

Yusuf, O. (1977). Mental Illness, the Least Known Problem in Ethiopia. Unpublished manuscript, Addis Ababa University. 